PRZEGLĄD RUSYCYSTYCZNY 2021, nr 2 (174)

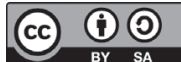

DOI 10.31261/pr.10081

\title{
SIMONA KORYČÁNKOVÁ
}

Masarykova univerzita, Brno, Česká republika

(iD http://orcid.org/0000-0002-7805-1604

ANETA ČERMÁKOVÁ

Masarykova univerzita, Brno, Česká republika

iD http://orcid.org/0000-0003-1498-2060

\section{ТРАНСФОРМАЦИЯ ЛЕКСИЧЕСКИХ ЕДИНИЦ-РЕАЛИЙ В ПРОЦЕССЕ ПЕРЕВОДА ПОВЕСТИ ШКОЛЬНИКИ ОЛЕГА ПАВЛОВА НА ЧЕШСКИЙ ЯЗЫК}

\author{
TRANSFORMATION OF LEXICAL UNITS-REALITIES \\ DURING THE PROCESS OF TRANSLATION OF THE STORY PUPILS BY OLEG PAVLOV INTO CZECH LANGUAGE \\ The purpose of the presented article is to analyze the specifics of the translation of a modern Russian literary text - \\ the story-memoir of Oleg Pavlov Pupils into Czech. The authors presented the translation as a transfer of non-equivalent \\ vocabulary, realities into another language while maintaining semantic and formal-aesthetic equivalence. The article \\ considers controversial or ambiguous solutions for translating selected realities that carry national connotations based on \\ specific adaptation techniques (transcription, analog, description, generalization, tracing, omission). \\ Keywords: fiction, transformation, source text, translation text, translation techniques
}

Диалог культур представляет собой один из самых древних актов коммуникации человечества, осуществляемых не только на уровне обмена информацией, но и на уровне взаимного обогащения национальной культуры элементами культуры другого народа ${ }^{1}$. В данном процессе перевод играет одну из решающих ролей посредника в переносе историко-культурных ценностей разных народов. Как отмечает Йозеф Сипко:

Всегда будет существовать многоязычие, всегда будут существовать этносоциальные коллективы, отличающиеся друг от друга формами выражения своих мыслей, своей этнокультурой. На этом межъязыковом

1 O. Richterek, Dialog kultur v uměleckém překladu, Mafy a Gaudeamus, Hradec Králové 1999, c. 5-6. 
и межнациональном рубеже стоит перевод, как средство сближения этнокультур ${ }^{2}$.

Ирина Алексеева считает, что перевод имеет «преодолевающую функцию [...], он помогает людям сблизиться, понять друг друга [...], преодолеть языковые и культурные барьеры» ${ }^{3}$.

Такую функцию выполняет и художественное творчество, его репродукция и воспроизведение художественного текста на другом языке. Иржи Левый дает следующее определение процесса художественного перевода:

Цель переводческого труда - постичь, сохранить, передать подлинник (информацию), а не создать новое произведение, не имеющее прототипов; целью перевода является воспроизведение. В процессе перевода материал одного языка замещается материалом другого, и, стало быть, все художественные средства языкового порядка переводчик создает сам, на родном языке, заново; таким образом, в области языка перевод - подлинное оригинальное творчество, перевод как произведение - художественная репродукция, художественное воспроизведение, перевод как процесс - подлинное творчество, перевод как тип искусства - промежуточная категория между исполнительским искусством и оригинальным творчеством ${ }^{4}$.

Необходимо, однако, отметить, что художественный перевод представляет собой также специфическую коммуникативную базу, имеющую своей опорной точкой общий итоговый эффект, т.е. тождественное влияние исходного текста и текста перевода на читателя. Милан Грдличка подчеркивает, что:

В интересах реализации успешной осмысленной коммуникации необходима ориентация на говорящего и предполагаемого слушателя, причем как в исходной литературной коммуникации (автор-читатель), так и во вторичном, производном отношении (переводчик-читатель). Однако мера направленности текста перевода на реципиента имеет свои пределы: переводчик должен при своей репродуктивно-творческой работе иметь в виду два решающих фактора: читателя, которому адресовано переведенное произведение, а также качество и доминантные черты оригинала. Переводчик должен стремиться к оптимальному решению этого 'двухвекторного' приема, к подходящему компромиссу (перев. С. Корычанкова) 5 .

2 Й. Сипко, Этнокультурный базис русско-словацких переводов, Náuka, Prešov 1999, c. 8.

3 И. С. Алексеева, Введение в переводоведение, Издательский центр Академия, Санкт-Петербург 2004, с. 9.

4 И. Левый, Искусство перевода, Прогресс, Москва 1974, с. 90.

5 M. Hrdlička, Literární překlad a komunikace, ISV nakladatelství, Praha 2003, c. 10 . 
Из вышесказанного следует, что мастерство перевода заключается в том, что переводчик должен искать оптимальный вариант для конкретного произведения, придерживаясь обдуманного, креативного подхода. Переводчик должен проникнуть в глубину мысли автора оригинала, понять его замысел и, следуя своей творческо-переводческой манере, трансформировать текст оригинала на язык перевода. Как отмечает Андрей Федоров:

Характерные особенности художественной литературы, проявление в каждом случае индивидуальной художественной манеры писателя, обусловленной его мировоззрением, влиянием эстетики эпохи и литературной школы, необозримое разнообразие как лексических, так и грамматических (в частности, синтаксических) средств языка в их различных соотношениях друг с другом, многообразие сочетаний книжно-письменной и устной речи в литературно преломленных стилистических разновидностях той и другой, - все это, вместе взятое, делает вопрос о художественном переводе чрезвычайно сложным 6 .

В центре нашего внимания будет один из важнейших компонентов перевода, представляющих для переводчика большую трудность - национальная и историческая окраска художественного произведения. Данные акценты воспринимаются в исходном тексте как нечто естественное, само собой разумеющееся. Однако перед переводчиком стоит серьезная проблема - найти подходящие приемы, с помощью которых он не ослабит специфику своеобразия историко-культурных особенностей действительности, описанной в тексте оригинала. Левый, анализируя проблематику адаптации исторических элементов, утверждает:

Наибольшей верности в передаче исторической и национальной специфики требует произведение, идейная нагрузка которого лежит в области единичного, в отражении определенной среды и эпохи, т.е. репортажи, путешествия, мемуары и пр.7.

Важно подчеркнуть, что национальная окраска никогда не выражается конкретными формальными особенностями произведения, кроме того, она не может быть сведена к одной кон-

6 А. В. Федоров, Основы общей теории перевода (лингвистические проблемы), Издательский дом Филология Три, Санкт-Петербург 2002, с. 276.

7 И. Левый, Искусство перевода..., с. 151. 
кретной лексической единице. «Национальная окраска всегда затрагивает целую совокупность черт в литературном произведении, целое сочетание особенностей, хотя некоторые из них могут быть более ярко отмечены ее печатью, чем другие» ${ }^{8},-$ уточняет Федоров.

Практика перевода показывает, что при переводе национальной окраски на иностранный язык важную роль играют слова, имеющие в своей семантике специфические культурные элементы, придающие контекстному значению слова или выражения особый характер. Сергей Влахов и Сидер Флорин выделяют в тексте слова-реалии, хотя, по их мнению, термин «реалия» в теории перевода не зафиксирован, в отличие, например, от понятий «безэквивалентная лексика» или «экзотизмы» ${ }^{9}$. Лингвисты и переводчики вносят в теорию перевода и другие понятия, обозначающие внеязыковой колорит, например, неполноэквивалентная лексика, фоновая лексика, национальные словесные образы, бытовые слова, лакуны, локализмы, варваризмы и др. ${ }^{10}$ Сипко вводит новый термин - этнокультурема. По его мнению, такие языковые элементы как этнокультуремы стоят в центре переводческого процесса, так как именно в них проявляется менталитет народа ${ }^{11}$.

Целью нашего исследования является рассмотрение употребленных приемов трансформаций русских реалий как специфичного феномена при адаптации исходного текста повести Школьники на чешский язык.

Произведение Школьники, написанное в 1999 г. $^{12}$, относится к жанру мемуарной автобиографической повести. Повествование построено на описании хронологических моментов из жизни главного героя-школьника. Эпизоды повести проникнуты мировосприятием уже взрослого рассказчика, вспоминающего о своем детстве. Демонстрация внутреннего мира

8 А. В. Федоров, Основы общей теории перевода..., с. 315.

9 С. Влахов, С. Флорин, Непереводимое в переводе, Международные отношения, Москва 1980 , с. 6.

${ }^{10}$ См. напр. Н. Ю. Ивойлова, А. А. Смирнова, К проблеме перевода реалий в художественном тексте, "Социальные и гуманитарные знания» 2017, т. 3, № 2, c. 183, http://j.uniyar.ac.ru/index.php/dnk/article/view/488 (15.08.2020).

${ }^{11}$ Й. Сипко, Этнокультурный базис русско-словацких переводов, Náuka, PreŠov 1999, c. 132.

12 О.О. Павлов, Школьники, «Октябрь» 1999, № 10, https://magazines.gorky. media/october/1999/10/shkolniki.html (08.09.2020). 
героя в большой степени влияет на использованные языковые средства и прагматику художественного текста. Темой повести является воспоминание о детстве, драках, мелком хулиганстве и судьбе близких членов семьи и друзей. Детали, на которые автор обращает внимание, переданы на историко-культурном фоне бывшего Советского Союза, а именно Москвы 1970-1980-х годов. Перевод данного произведения был нами осуществлен в 2019-2020 гг. ${ }^{13}$.

Практика перевода основывается на ранее изученных и описанных способах передачи безэквивалентной лексики ${ }^{14}$, причем одной из основных переводческих трансформаций при переводе реалий можно считать переводческую транслитерацию и транскрипцию, т.е. адаптацию исходного слова или словосочетания посредством переписи их графической или звуковой формы на язык перевода.

В повести Школьники часто встречаются разные виды реалий, например, топонимы, для перевода которых можно употребить транскрипцию, напр.: Свиблово (Sviblovo), Марьина Роща (Marjina Rošča), Яуза (Jauza), ВДНХ (VDNCh). C другой стороны, некоторые антропонимы мы решили транскрибировать и одновременно адаптировать, то есть уподобить нормам чешского языка. К примеру, в повести встречается краткая форма имени Константин, Костик, которую мы уподобили чешскому звучанию посредством суффикса -ík (Kostík; аналогично Павлик - Pavlík); в случае прозвища Раушиха мы заменили исходную форму транскрибированным эквивалентом с суффиксом -ісе (Raušice). Фамилию Кривоносов, которая упоминается и обыгрывается в первой главе повести, мы также решили уподобить чешскому звучанию (Křivonosov). Таким образом удалось сохранить национальный колорит, а также воссоздать на языке перевода как можно больше русских реалий.

Специфическим примером транскрибированного перевода можно считать трансформацию реалии «ушанка» на чешский язык:

${ }^{13}$ Перевод повести Школьники готовится к изданию. На сегодняшний день была на чешский язык переведена лишь одна повесть Павлова, Конец века, вошедшая в книгу Antologie ruských povídek.

${ }^{14}$ См. напр. Л.С. Бархударов, Язык и перевод (Вопросы общей и частной теории перевода), Международные отношения, Москва 1975, с. 96-103. 
ИТ: «[...] ничего геройского, разве что автомат сжимает в руках, сам в тулупе деревенском и ушанке, какой же это герой!»

TП: «Hrdinského na něm není nic, na sobě má prachobyčejnej kožich a na hlavě ušanku, vždyt jen ten samopal drží v rukách, no jakej je tohle hrdina!»

На основе проделанного анализа ясно, что этнокультурема «ушанка» была транскрибирована уже в качестве заимствования данного слова на чешский язык, так как в чешский быт вошел этот русский головной убор и вместе с ним заимствовалось и название, уподобленное нормам чешского языка - ušanka. Для перевода был выбран уже существующий заимствованный аналог.

При переводе указанного выше предложения следует обратить внимание на реалию - тулуп (деревенский). Данная реалия в чешском языке не используется, поэтому нельзя использовать прием транскрипции. Для полного переноса всех ее смысловых оттенков подходит описательный перевод, который, однако, редко используется в переводе художественного текста, поскольку он загружает текст и нарушает его связность. В данном примере применяется прием генерализации - подобранный эквивалент «kožich» можно перевести как «шуба». Благодаря прилагательномy «prachobyčejnej» (эквивалент прилагательного «деревенский» в значении 'ничем не примечательный, обычный') была достигнута желательная конкретизация.

Данное предложение представляет собой внутренний монолог рассказчика, в связи с чем в прилагательном «prachobyčejný» применено нелитературное окончание (-еј вместо -ý), которое указывает на неформальную речь главного героя, мальчика.

Невозможность использовать прием транскрипции приводит к поиску других способов передачи названий реалий. Разъяснительный перевод позволяет раскрыть значение лексической единицы с помощью ее описания.

ИТ: «Все они, платья, шиты были по одному фасону, навроде сарафана с рукавчиками, да из одной старомодной ткани, из кримплена».

TП: «V̌̌echny tyhle pytlovité šaty s rukávky byly ušité podle jednoho střihu, a navíc byly všechny ze stejné staromódní látky, z umělého krimplenu».

В тексте перевода встречается слово «сарафан», которое было заимствовано в чешский язык путем транскрипции, причем одновременно произошло удлинение ударного гласного - sarafán. 
Чешское слово «sarafán» употребляется для обозначения одного из традиционных видов русской национальной женской одежды, однако в русском тексте лексема «сарафан» употреблена в значении обычного платья со вшитыми рукавами. На основе рассмотрения авторского использования данного слова в чешском тексте применяется описательный перевод - «pytlovité šaty» (в значении 'платье не очень удачного, свободного покроя’). Прилагательное «pytlovitý» было подобрано как акцентирующее выражение, которое помогает читателю получить представление о описываемой невзрачной наружности учительницы главного героя.

Для перевода слова «кримплен» использован прием расширения информационного ядра ${ }^{15}$. Ткань кримплен (krimplen) известна прежде всего старшему поколению чешских читателей. В настоящее время эта ткань практически не используется, поэтому данное выражение дополняется в переводе прилагательным «umělý» («искусственный»), уточняющим основное качество кримплена.

Описательный перевод был нами применен также при переводе нижеследующего предложения:

ИТ: «Восьмилетка для него была концом учебы - как и многие, дядя Федор надумал идти в училище, чтобы получить профессию автослесаря». ТП: «Základka pro něj končila v osmé tř́ídě, protože se jako i mnoho dalších rozhodl, že pak půjde na učiliště a vyučí se automechanikem».

В ЧССР существовали восьмилетние школы (восьмилетки), однако в настоящее время чешские школьники должны получить обязательное девятилетнее школьное образование. Учитывая этот факт, выражение «восьмилетка» может быть непонятным для молодого поколения читателей. Для решения этой проблемы был применен прием генерализации. Подобранный эквивалент «základka» (в значении «основная школа») имеет разговорный характер и представляет собой сокращенное слово с суффиксом -к-а. Для сохранения главного значения исходной единицы в переводе в данной части предложения была применена лексико-синтаксическая замена. Одновременно, было при-

${ }^{15}$ «Rozšsiření informačního základu» cм. E. Vysloužilová, M. Machalová, Cvičebnice překladu pro rusisty: politika, ekonomika, Univerzita Palackého v Olomouci, Olomouc 2011, c. 15 . 
ведено указание на последний класс основной школы («základka pro něj končila v osmé třídě» — «основная школа для него окончилась в восьмом классе»).

Прием использования аналога заключается в употреблении соответствующего по значению слова и словосочетания в языке перевода. В переводе повести Павлова нами используется такой прием для передачи значения устойчивого словосочетания «вторая смена»:

ИТ: «На школьный двор вырвались после уроков своей второй смены, уже в сумерках».

ТП: «Už se stmívalo, když jsme po našem odpoledním vyučování vtrhli do školního dvora».

В русских школах раньше обучение проходило в две смены. Такой реалии в настоящих чешских школах нет, более того, при буквальном переводе данной реалии (druhá směna) была бы нарушена связность текста, поскольку данное словосочетание на чешском языке отсылает к работе на заводе. Вторая смена начинается после обеда, поэтому в переводе используется прием субституции - «odpolední vyučování» (в значении “занятия после обеда'). Использованное словосочетание является в данном контексте функциональным аналогом, выявленным на основе контекста. Хотя оно не передает все смысловые оттенки исходной единицы (особенно исторический, этнокультурный подтекст), сохраняется ее основной смысл.

В качестве примера субституции можно привести и выражение «кирзовые сапоги»:

ИТ: «Зимой шатались по улицам в кирзовых сапогах и в телогрейках, пугая прохожих в сумерках своим видом».

TП: «V zimě se venku potloukali v keprových holínkách a prošívaných vatácích, a když se začalo stmívat, svým zevnějškem děsili kolemjdoucí».

Кирза - плотная прочная хлопчатобумажная ткань, которая до сих пор применяется при изготовлении спецодежды и элементов военного снаряжения в России, однако, малоизвестна в чешской среде. Посредством Базы переводческих эквивалентов Treq ${ }^{16}$ были выявлены возможные аналоги, а именно

${ }^{16}$ Treq. Databáze překladových ekvivalentů. Ústav Českého národního korpusu FF UK, Praha 2015, https://treq.korpus.cz/index.php (25.8.2020). 
«keprové holínky» или "plátěné vysoké boty». Кипер (kepr) представляет собой прочную хлопчатобумажную ткань, которая, с одной стороны, не используется для изготовления обуви, с другой же стороны, отсылает к ткани, применение которой довольно ограничено, как и в случае кирзы. Перевод-субституция «keprové holínky» сохраняет некую жаргонную характеристику, которая свойственна и словосочетанию «кирзовые сапоги». Читатель может представить себе сапоги, изготовленные из ткани, в чем и заключается их отличие от резиновых сапог. Результатом перевода является словосочетание-неологизм «keprové holínky».

В ходе работы над переводом необходимо было рассмотреть возможности применения генерализации:

ИТ: «Дядя Федор знал, что его ждет ПТУ, и давно перестал бояться школы $[\ldots] »$.

TП: Strejda Fjodor věděl, že ho čeká učňák, tak už se školy nebál.

Выражение «профессионально-техническое училище» - (ПТУ) можно перевести на чешский язык как «střední odborné učiliště» - (SOU), однако это сокращение не уместно в данном контесте из-за более конкретной сферы его употребления. Использованный прием генерализации отсылает читателя к обобщающему выражению для профессиональных учебных заведений - učiliště (училище) - причем в его разговорном варианте «učňák», типичном для школьного жаргона.

В нескольких случаях при адаптации текста нами использовался прием опущения, к примеру, при переводе реалий без семантической нагрузки. Проблематику такого подхода при трансформации исходного текста рассматривал Сипко:

Несмотря на наши общие славянские корни, многие этнореалии имеют в конкретных культурно-исторических традициях разную семантику, различное осмысление. Поэтому в процессе перевода часто встречаемся с пропусками этих реалий, их неточным переводом, вследствие чего возникает неправильное осмысление данных реалий ${ }^{17}$.

${ }^{17}$ Й. Сипко, Этнокультурный базис русско-словацких переводов, Náuka, Prešov 1999, c. 8. 
В качестве примера приводим описание работы переводчика при адаптации выражения «мичуринские яблоки»:

ИТ: В саду Ботаническом трясли мичуринские яблоки.

ТП: V Botanické zahradě jsme setřásali jablka, [...]

В чешском языке в прошлом веке распространилось слово «mičurinec» («мичуринец», в значении 'растениевод-любитель', образованное от фамилии Ивана Мичурина, русского биолога и селекционера). Однако буквальный перевод исходного словосочетания «мичуринские яблоки» мог бы представлять для большинства читателей определенный мичуринский сорт яблок. На реалии «мичуринский» не ставится смысловой акцент, само слово в исходном тексте используется один раз. Из анализа следует, что описательный перевод усложнил бы текст нежелательным уточнением, поэтому был использован прием опущения («мичуринские яблоки» - «jablka»).

Особый вид опущения реалии можно отметить также в замене слов «кирзачи» - «holiny»:

ИТ: «А на кирзачи выклянчил у нее же обманом десять рублей, обещая, что потрачу на покупку каких-то дефицитных кроссовок, [...]».

ТП: «A na holiny jsem si u ní vyškemral deset rublo̊, protože jsem jí zalhal a slíbil, že peníze utratím za nějaké nedostatkové tenisky».

Значение русского выражения «кирзачи», т.е. кирзовые сапоги, можно перевести на чешский язык «keprové holínky». Аналогично используется устойчивое словосочетание "gumové holínky» («резиновые сапоги»), образующее даже разговорный сокращенный вариант - «gumáky». Однако для перевода был выбран более подходящий по смыслу разговорный эквивалент - «holiny», отсылающий к сапогам из любого материала. Здесь нами применен прием генерализации, что способствовало желаемому восприятию переводного текста.

Калькирование как прием перевода заключается в трансформации слова-реалии, причем его использование зависит от возможности замены или составных частей слова, или словосочетания, или его значения. В качестве примера можно привести ситуативные реалии, которые отражают обычаи и привычки народа. 
Помимо обязательной передачи ситуативной реалии на основе полных знаний о ней, она должна быть прокомментирована. Возможен краткий комментарий внутри текста. [...] В художественном тексте возможен лишь внетекстовой комментарий (примечание) ${ }^{18}$.

ИТ: «Кто-то видел и рассказывал, что я завалил несколько «пятаков», обознался или соврал, но сам я не открывал рта и опустошенно молчал». ТП: «Někdo vyprávěl, že viděl, jak jsem to nandal několika «pětákům». Bud' to pomotal, nebo kecal, ale já sám jsem ani necekl a zaraženě jsem mlčel».

Аналогично сокращению в русском языке «пятак» с использованием норм чешского словообразования возникло слово «pěták», обозначающее вражескую ребяческую группу мальчиков из московского Пятого микрорайона, что и описывается в исходном тексте.

В процессе перевода следующей реалии мы обратились к работе Сипко Этнокультурныцй базис русско-словацких переводов, в которой был найден эквивалент сокращения «стройбат» - «pétépáci»:

ИТ: «А на кирзачи выклянчил у нее же обманом десять рублей, обещая, что потрачу на покупку каких-то дефицитных кроссовок, и долго ходил с дружками у стройбатовских казарм, пока один служивый не перекинул пару стоптанных сапог через забор, за что я тут же просунул в щель свой червончик, обмирая и от гордости за себя, и от счастья».

ТП: «A na holiny jsem si u ní vyškemral deset rublo̊, protože jsem jí zalhal a slíbil, že peníze utratím za nějaké nedostatkové tenisky. Dlouho jsem pak s ostatními chodil okolo kasáren pétépáků, dokud mi jeden voják nepřehodil přes plot pár ochozených holínek. Hned jsem mu za ně štěrbinou prostrčil svoji desetirublovku. Umíral jsem štěstím a byl jsem radostí bez sebe».

Аббревиатура «стройбат» возникла из словосочетания «строительный батальон» - «stavební prapor», однако в контексте повести она не воспринимается естественной (kasárny stavebního praporu - три слова, несогласованное определение). Сипко предлагает для перевода разговорный эквивалент "pétépáci» ${ }^{19}$, возникший из сокращения PTP - Pomocné technické prapory, который более уместен в нашем переводе благодаря разговорному характеру и схожей этимологии. Характер строительных батальонов в CCCP и pomocných technických

${ }^{18}$ И. С. Алексеева, Введение в переводоведение, Издательский центр Академия, Санкт-Петербург 2004, с. 173.

19 Й. Сипко, Этнокультурный базис русско-словацких переводов, Náuka, Prešov 1999, c. 53. 
praporů в ЧССР не совпадает полностью, так как РТР не всегда размещались в казармах, а скорее в пустых гостиницах, замках, хозяйственных постройках или даже конюшнях. Поэтому для перевода мы изначально хотели использовать выражение — «ženisté», «ženijní pluk», однако деятельность РТР в большей степени совпадает с деятельностью стройбата в области строительства. Все изложенные факты привели к тому, что предпочтение было отдано эквиваленту «kasárny pétépáků », который в большей мере соответствует семантическому ядру исходного слова.

Итак, мы рассмотрели некоторые примеры приемов, использованных при переводе русского художественного текста на чешский язык. Анализ способов передачи слов-реалий, представляющих специфичный феномен, на котором держится историко-культурный фундамент произведения, показал, что в возникновении текста перевода решающую роль играет смысловая точность - особенно тогда, когда не нарушается художественность текста перевода.

\section{REFERENCES}

Alekseyeva, Irina. Vvedeniye v perevodovedeniye. Sankt-Peterburg: Izdatel'skiy tsentr Akademiya, 2004 [Алексеева, Ирина. Введение в переводоведение. Санкт-Петербург: Издательский центр Академия, 2004].

Barkhudarov, Leonid. Yazyk i perevod (Voprosy obshchey i chastnoy teorii perevoda). Moskva: Mezhdunarodnyye otnosheniya, 1975 [Бархударов, Леонид. Язык и перевод (Вопросы общей и частной теории перевода). Москва: Международные отношения, 1975].

Fedorov, Andrey. Osnovy obshchey teorii perevoda (lingvisticheskiye problemy). Sankt-Peterburg: Izdatel'skiy dom Filologiya Tri, 2002 [Федоров, Андрей. Основы общей теории перевода (лингвистические проблемы). СанктПетербург: Издательский дом Филология Три, 2002].

Hrdlička, Milan. Literární překlad a komunikace. Praha: ISV nakladatelství, 2003.

Levyy, Irzhi. Iskusstvo perevoda. Moskva: Progress, 1974 [Левый, Иржи. Искусство перевода. Москва: Прогресс, 1974].

Richterek, Oldřich. Dialog kultur v uměleckém překladu. Hradec Králové: Mafy a Gaudeamus, 1999.

Sipko, Yozef. Etnokul'turnyy bazis russko-slovatskikh perevodov. Prešov: Náuka, 1999 [Сипко, Йозеф. Этнокультурный базис русско-словацких переводов. Prešov: Náuka, 1999]. 
Влахов, Сергей, Флорин, Сидер. Непереводимое в переводе. Москва: Международные отношения, 1980 [Vlakhov, Sergey, Florin, Sider. Neperevodimoye $v$ perevode. Moskva: Mezhdunarodnyye otnosheniya, 1980].

Vysloužilová, Eva, Machalová, Milena. Cvičebnice překladu pro rusisty: politika, ekonomika. Olomouc: Univerzita Palackého v Olomouci, 2011. 